\title{
Identifying rice grains with premium nutritional quality among on-farm germplasm in the highlands of Northern Thailand
}

\author{
T. Sreethong ${ }^{1}$, C. Prom-u-thai ${ }^{1,2}$, B. Rerkasem ${ }^{3}$, B. Dell ${ }^{4}$ and S. Jamjod ${ }^{1,2}$ \\ ${ }^{1}$ Agronomy Division, Department of Plant and Soil Sciences, Faculty of Agriculture, Chiang Mai University, Chiang Mai \\ 50200, Thailand; ${ }^{2}$ Lanna Rice Research Center, Chiang Mai University, Chiang Mai 50200, Thailand; ${ }^{3}$ Plant Genetic \\ Resource and Nutrition Laboratory, Chiang Mai University, Chiang Mai 50200, Thailand; ${ }^{4}$ Chancellery, Murdoch \\ University, Perth, WA 6150, Australia
}

Corresponding Author: C. Prom-u-thai, chanakan.p@cmu.ac.th; chanakan15@hotmail.com

Received: 20 January 2020 / Accepted: 9 June 2020 / Published: 5 July 2020

(c) 2020 Codon Publications

OPEN ACCESS (C) (우)(2)

RESEARCH ARTICLE

\begin{abstract}
Local rice varieties with premium nutritional quality grains are beneficial to consumers, and their genetic traits may be deployed in breeding programmes for many purposes. This study explores grain quality characteristics with health implications of rice germplasm maintained and used by farmers in the highlands of Northern Thailand. Concentrations of iron (Fe), zinc ( $\mathrm{Zn})$, phenols and anthocyanin and anti-oxidative capacity were determined in the caryopsis without husk of 77 samples of rice seed collected from farmers. Entries with the highest grain quality characteristics identified were grown together with four standard check varieties at two different elevations in a farmer's field at Mae Wang District of Chiang Mai province ( $800 \mathrm{~m}$ above mean sea level), as well as in pots at Chiang Mai University (CMU) (330 m above mean sea level). The grain quality characteristics were determined at maturity, separately for 10 individual plants grown at CMU. A wide variation in all the grain quality characteristics was found among samples grown in the farmer's field. There were approximately twofold differences in the lowest and highest Fe and $\mathrm{Zn}$ concentrations, especially high variation in contents of phenols and anthocyanin and anti-oxidative capacity found in grain with purple pericarp. The top entries identified from the farmer's seed had significantly higher anthocyanin concentration and anti-oxidative capacity than the check varieties when grown together at Mae Wang and CMU, in spite of the strong locality-specific effects on these characteristics. Further variation was found in the grain quality characteristics within each of the selected farmer's seed samples. Quality improvement could thus be made by either eliminating the poorest performing lines or development of single-seed descent lines from the top-performing plants. The desirable genetic traits can also be used in breeding programme for improvement of grain yield as well as cooking and nutritional quality.
\end{abstract}

Keywords: local rice, iron, zinc, phenols, anthocyanin, anti-oxidative capacity

\section{Introduction}

Local rice varieties are a valuable resource for traits that confer grain quality characteristics with health benefit implications (Panomjan et al., 2016; Prom-u-thai and Rerkasem, 2001; Xiongsiyee et al., 2018), as well as for adaptation to environmental factors of both biotic and abiotic stresses that are lost among the modern improved varieties, resulting in susceptibleness to a wide spread environmental stresses (Kumar et al., 2004; Laenoi et al., 2015; Naruebal, 2009; Oupkaew et al., 2011; Wissuwa and Ae, 2001). The quality characteristics of rice with health implications, which are a concern among rice consumers, include contents of the minerals $\mathrm{Fe}$ and $\mathrm{Zn}$, the bioactive compounds anthocyanin and phenols and anti-oxidant capacity. Rice consumers are especially prone to health problems associated with these minerals and compounds because their presence in rice is much lower in 
concentration than in other staple crops such as wheat and barley (Demirbas, 2005; White and Broadley, 2005). Inadequate consumption of Fe and $\mathrm{Zn}$ results in impaired growth, development and immune system, especially among the children in rice consumption regions (Black, 1998; Keen and Gershwin, 1990; Lozoff and Georgieff, 2006). On the other hand, bioactive compounds with medicinal and industrial potential, such as anthocyanin and antioxidants, have been reported to prevent free radicals that stimulate cancer and cell injury (Kehrer, 1993) and inhibit activity of some digestive enzymes that can increase the impact of diabetes (Boue et al., 2016).

Improving the minerals and bioactive compounds in rice grain by bio-fortification, for example, breeding strategy and agronomic managements, is suggested as a promising way to alleviate the problems among population whose staple food is rice (Cakmak, 2010; Kutman et al., 2010). To do this, the source of genetic material with wide variation of nutrition qualities is required to achieve the desired goal in both grain nutrition quality and its production, especially in breeding programme. Interestingly, local rice varieties with desirable quality traits are being exploited in the emerging market for rice with special quality (e.g. Boonsit et al., 2010; Panomjan et al., 2016) as well as to directly benefit those who consume the rice they grow and they also provide a source of genetic traits in breeding programmes. On the other hand, commercialisation of rice production, especially in the countries such as Thailand, Vietnam, China and India where a great amount of the production is consumed and exported annually, has led to the replacement of local rice varieties by only a few mega-varieties; however, local rice varieties are still grown by farmers in a few areas, including the highlands of Laos (Xiongsiyee et al., 2018) and Northern Thailand (Jamjod et al., 2017), which are part of the centre of diversity for Oryza sativa (Harlan, 1992). Thus, identifying nutritional quality traits among the local rice varieties is not only beneficial to health-conscious consumers, but would also allow the further in-depth physiological study and breeding programme. In particular, programmes assisting with modern molecular techniques would allow to rapidly improve new rice varieties for the farmer's desirable traits, such as photoperiod insensitivity with high yield, which is generally lacking in the local varieties.

This study attempted to explore grain nutritional quality characteristics of rice germplasm maintained and used by farmers in three provinces-Chiang Mai, Chiang Rai and Mae Hong Son-where a substantial proportion of the local rice germplasm in Thailand may still be found. In the previous study, 77 samples of rice seed were collected and analysed for $\mathrm{Fe}, \mathrm{Zn}$, phenols, anthocyanin and anti-oxidative capacity (Jamjod et al., 2017). The highest quality traits were selected for two samples each
(Kam Wiangsa; KWS was selected for both Fe and phenol qualities) for the current study. The nutritional quality of the selected lines was also determined between the growing locations. The results of this study would be very useful information, especially in breeding programmes for rice of high nutritional values as well as its utilisation for health benefit purposes.

\section{Materials and methods}

\section{Farmers' seed samples}

In the previous study, 77 samples of rice seed were collected from farmers in Chiang Mai, Chiang Rai and Mae Hong Son (Figure 1) (Jamjod et al., 2017). Information recorded for each sample included the Global Positioning System (GPS) position of the farm and the soil-water system under which the rice was grown (upland = grown on aerobic soil on slope; wetland = grown on levelled field, soil submerged under a few $\mathrm{cm}$ of water). A100 g subsample was taken from each collected sample and dehusked in a sample mill machine (Ngek Seng Huat model $\mathrm{P}-1$, Thailand) to produce brown rice (endosperm with intact embryo and pericarp). Pericarp pigmentation was determined visually as white (not pigmented), purple and red, and the amylose content of the brown rice was determined by iodine-amylose colour development (Juliano, 1971) using a spectrophotometer (Hitachi model U-1900, Japan) at $620 \mathrm{~nm}$. Grain nutritional quality characteristics of the brown rice were determined: Fe and $\mathrm{Zn}$ by atomic absorption spectrophotometry (Hitachi Model Z-8230, Japan) after dry-ashing at $535{ }^{\circ} \mathrm{C}$ for $8 \mathrm{~h}$ (Allan, 1961); phenols by Folin Ciocalteu's method (Folin and Denis, 1912), anthocyanin by the $\mathrm{pH}$-differential method (Escribano-Bailón et al., 2004; Wrolstad et al., 2001) and trolox equivalent anti-oxidative capacity (TEAC) by the DPPH free radical scavenging method (Yue and $\mathrm{Xu}$, 2008). The highest concentration of Fe, $\mathrm{Zn}$, phenols and anthocyanin and anti-oxidative capacity were selected for two samples each (Kam Wiangsa; KWS was selected for both Fe and phenol qualities) for the current study.

\section{Comparing selected lines with top quality at Mae Wang}

The nine selected lines were grown together with four standard check varieties at Mae Wang District of Chiang Mai province, Thailand $\left(\mathrm{N} 18.4254^{\circ}\right.$, E98.3412 ${ }^{\circ}$; $800 \mathrm{~m}$ above mean sea level) from July to December 2014, with soil-water condition in accordance with their management on-farm (Table 1). The upland rice lines were grown on well-drained soil with flood irrigation when necessary; the wetland lines were grown on waterlogged soil (5-10 cm of water maintained above the soil surface from transplanting to maturity). Each of the selected lines and check varieties was grown as single plants, with $0.25 \mathrm{~m} \times 0.25 \mathrm{~m}$ spacing in $2 \times 4 \mathrm{~m}^{2}$ plots, arranged in duplicated blocks. The crop was fertilised with 


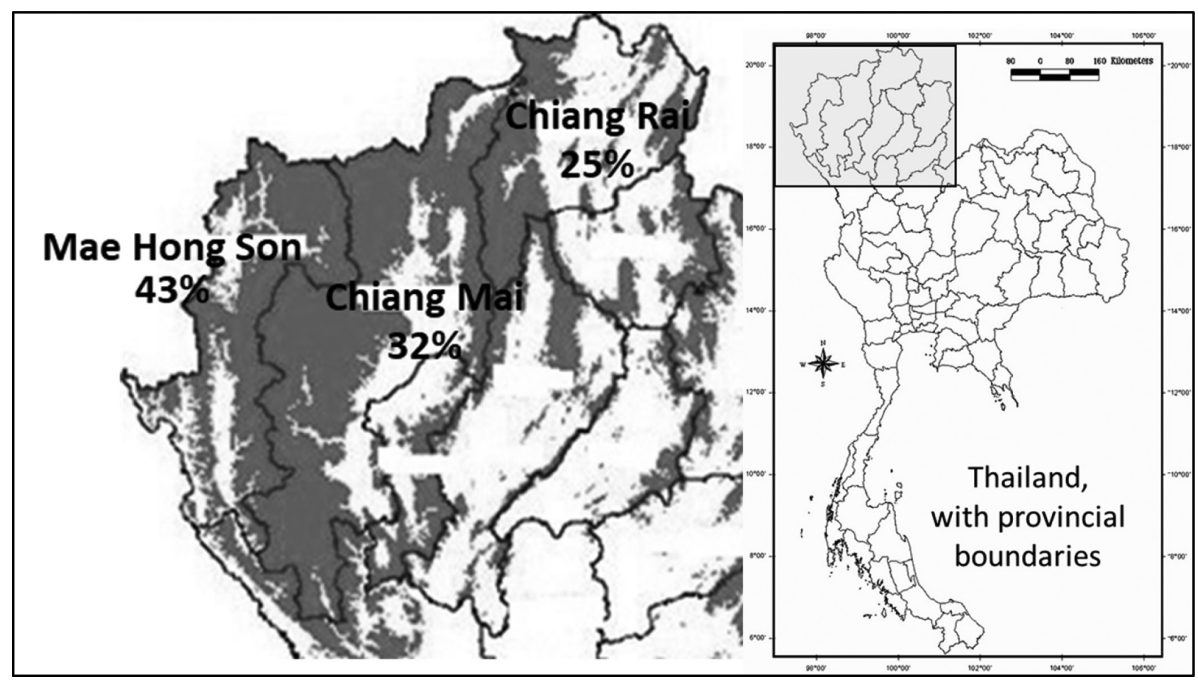

Figure 1. Local rice varieties sampling area in the highlands of Northern Thailand. The number under the province name is the percentage of samples evaluated. The symbol $\square$ in the map indicates mountainous area $500 \mathrm{~m}$ above mean sea level and lower lying areas between the mountains.

Table 1. Selected local rice varieties with the highest iron, zinc, phenol and anthocyanin concentrations and anti-oxidative capacity grown together with four check varieties for comparison at Mae Wang, a highland site in Northern Thailand.

\begin{tabular}{llll} 
Top quality for & \multicolumn{1}{c}{ Variety } & \multicolumn{1}{c}{ Location $\left(^{\circ}\right)$} & Soil-water management \\
\hline Iron & KWS (Kam Wiang Sa) & N19.4052, E98.1242 & Wetland \\
& BK (Bian Koo) & N19.8921, E100.2967 & Upland \\
Zinc & BTN (Bue Tor Na) & N17.8770, E97.9248 & Upland \\
& BB (Bue Bang) & N17.5353, E97.5224 & Upland \\
Phenols & KWS (Kam Wiang Sa) & N19.4052, E98.1242 & Wetland \\
& KS (Kao Saeng) & N19.4052, E98.1242 & Upland \\
Anthocyanin & PES037 (Pee-Ee-Su 1) & N18.3748, E98.3748 & Upland \\
& PES057 (Pee-Ee-Su 2) & N18.3748, E98.3748 & Upland \\
Anti-oxidative capacity & DMO (Daew Ma O) & N19.7332, E99.5280 & Upland \\
& KAK (Kam Akha) & N19.7332, E99.5280 & Upland \\
Check varieties for & KDML105 (non-glutinous, mega-variety) & Wetland \\
Iron, Zinc & RD6 (glutinous, mega-variety) & Wetland \\
Phenols, anthocyanin, & KDK (purple rice) & & Upland \\
anti-oxidative capacity & KHCMU (purple rice) & & Upland \\
\hline
\end{tabular}

$60 \mathrm{~kg}$ nitrogen $(\mathrm{N}) \mathrm{ha}^{-1}, 30 \mathrm{~kg}$ phosphorus $(\mathrm{P}) \mathrm{ha}^{-1}$ and 30 $\mathrm{kg}$ potassium $(\mathrm{K}) \mathrm{ha}^{-1}$, which was split two times between tillering and flowering. Days to flowering were determined from the germination date to $50 \%$ flowering of each plot. Plant height and the number of panicles per hill were determined on 10 representative plants of each line and grain yield from $1 \mathrm{~m}^{2}$ internal area of each plot, at maturity. $\mathrm{Nu}$ tritional quality characteristics were determined in the same way as for farmers' seed described above.

\section{Variation within seed samples}

Variation was evaluated in the seed of 10 individual plants of each selected seed sample and the check varieties grown at Chiang Mai University (CMU), Thailand (N19.4052 ${ }^{\circ}$ E98.1242 $; 330 \mathrm{~m}$ above mean sea level) from July to December 2014. The plants were grown in pots (Ø30 cm, $30 \mathrm{~cm}$ deep) containing $15 \mathrm{~kg}$ of sandy loam soil of the Sansai series, at five plants per pot, with soil-water 
management in accordance with their management onfarm, that is, aerobic well-drained soil for the upland ecotype and waterlogged soil for the wetland ecotype. The plants were fertilised on a surface area basis in the same way as described above. At maturity, plants were harvested individually and threshed by hand. Quality characteristics of the grain were determined as described above, separately for each plant.

\section{Data analysis}

The data were evaluated using the analysis of variance (ANOVA) and mean that were significantly different and were separated by the least significant difference test (LSD) at $P<0.05$.

\section{Results}

A considerable variation was found among the selected lines that were grown in farmers' fields in the highlands of Northern Thailand (Table 2). Among individual entries, there were approximately twofold differences in the lowest and highest Fe and $\mathrm{Zn}$ concentrations, but much larger variation in the contents of phenols and anthocyanin and anti-oxidative capacity. The highest total phenolic content was five times the lowest one,

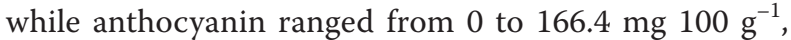
and anti-oxidative capacity ranged from 1.9 to $1811.5 \mathrm{mg}$ Trolox $100 \mathrm{~g}^{-1}$. Thus, entries with exceptionally high levels of nutritional quality characteristics measured were identified. Two entries with the highest anthocyanin concentration, PES037 and PES057, were from the same village $\left(\mathrm{N} 18.3748^{\circ}, \mathrm{E} 98.3748^{\circ}\right)$, and similarly were the two with the highest anti-oxidative capacity, Daew Ma $\mathrm{O}(\mathrm{DMO})$ and Kam AKha (KAK) (N19.7332 ${ }^{\circ}$, E99.5280 $)$.

The entries of local rice varieties selected for grain quality were all grown on-farm as upland rice, except KWS which was a wetland ecotype, and had very different appearance from the mega-variety checks, KDML105 and RD6 (Figure 2 and Table 3 ). They all had medium to bold grain type, in contrast to the slender grain KDML105 and RD6, and all except three had glutinous grain with pigmented pericarp, although the hull colour ranged from purple, straw colour

Table 2. Grain quality characteristics of farmers' rice seed samples from the highlands of Northern Thailand by plant and grain type.

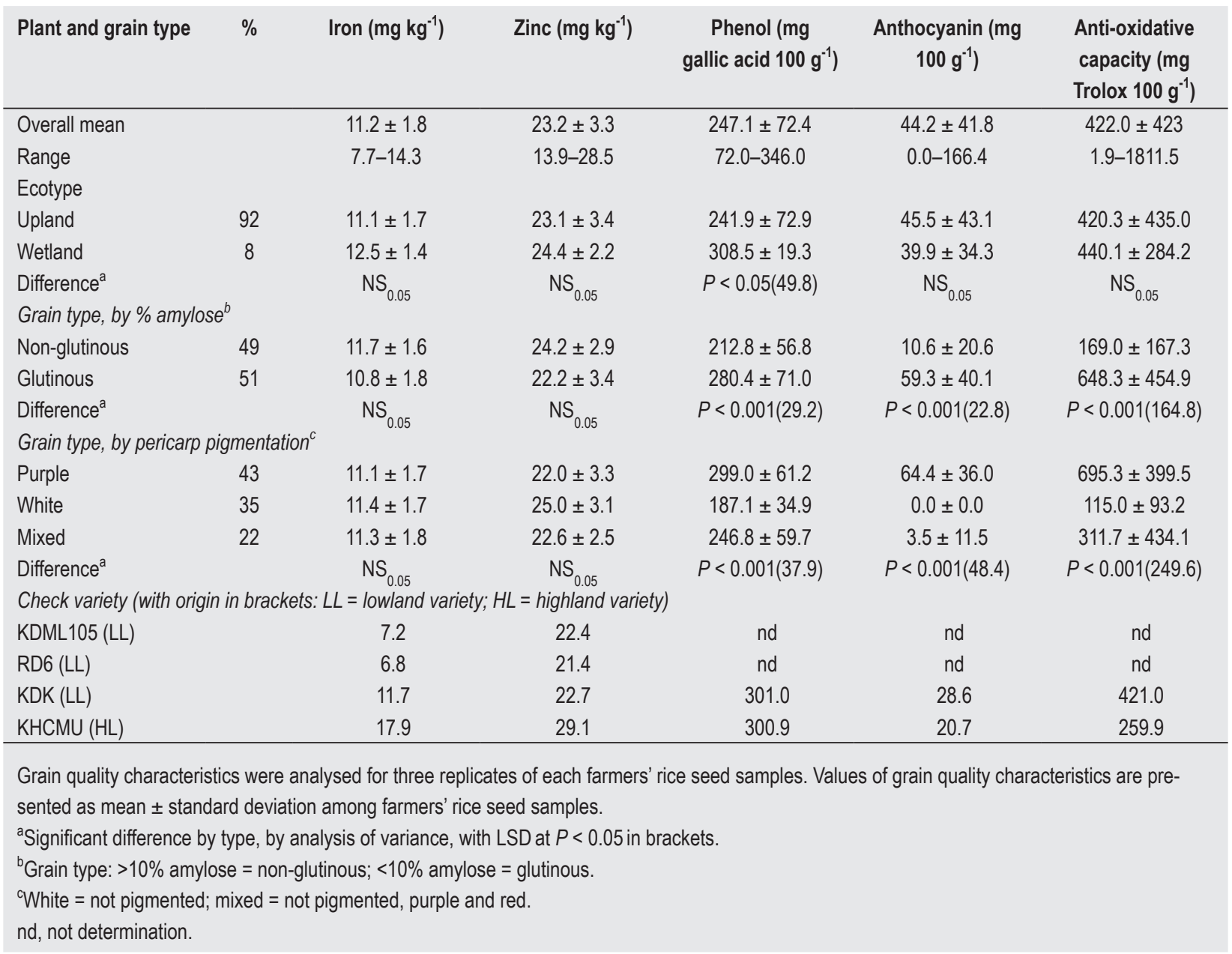




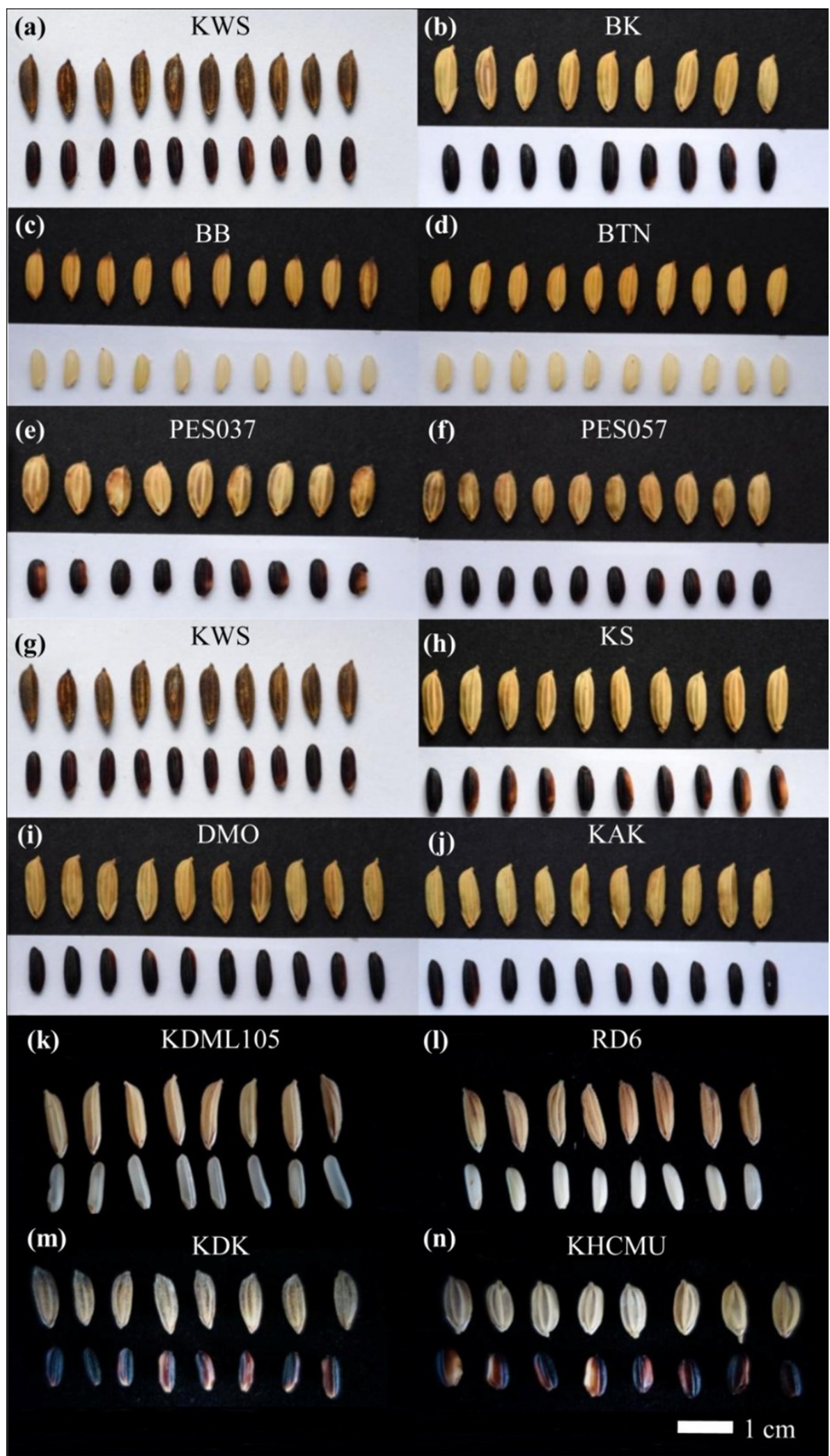

Figure 2. Paddy and brown rice grain of selected lines for high grain Fe, KWS (a) and BK (b); Zn, BTN (c) and BB (d); anthocyanin, PES037 (e) and PES057 (f); phenol, KWS and KS (h); anti-oxidative capacity, DMO (i) and KAK (j); with check varieties KDML105 (k), RD6 (l), KDK (m) and KHCMU (n). 
Table 3. Selected local rice varieties with the highest iron, zinc, phenol and anthocyanin concentration and anti-oxidative capacity.

\begin{tabular}{|c|c|c|c|c|c|c|c|}
\hline \multirow[t]{2}{*}{$I^{a}$} & \multirow{2}{*}{$\begin{array}{l}\text { Variety } \\
\text { name }\end{array}$} & \multirow[t]{2}{*}{ Ecotype } & \multicolumn{2}{|c|}{ Grain dimension $^{b}$} & \multirow{2}{*}{$\begin{array}{l}\text { Grain starch } \\
\text { Type }^{c}\end{array}$} & \multirow[t]{2}{*}{ Hull colour } & \multirow[t]{2}{*}{ Pericarp colour } \\
\hline & & & Length (mm) & Shape & & & \\
\hline $56-037$ & PES037 & Upland & 5.5 & Bold & Waxy & Straw + purple tint & Purple \\
\hline $56-057$ & PES057 & Upland & 5.8 & Bold & Waxy & Straw + purple tint & Purple \\
\hline $56-078$ & BB & Upland & 6.4 & Medium & Non-waxy & Straw & White \\
\hline $56-092$ & BTN & Upland & 6.4 & Medium & Non-waxy & Straw & White \\
\hline $56-151$ & DMO & Upland & 7.3 & Medium & Waxy & Straw + purple tint & Purple \\
\hline $56-153$ & KAK & Upland & 7.4 & Medium & Waxy & Straw & Purple \\
\hline $56-242$ & KWS & Wetland & 7.2 & Medium & Waxy & Purple & Purple \\
\hline $56-260$ & BK & Upland & 7.2 & Medium & Non-waxy & Straw & Purple \\
\hline $56-279$ & KS & Upland & 7.5 & Medium & Waxy & Straw + purple tint & Purple \\
\hline \multicolumn{8}{|c|}{ Check variety } \\
\hline KDML105 & & Wetland & 7.5 & Slender & Non-waxy & Straw & White \\
\hline RD6 & & Wetland & 7.2 & Slender & Waxy & Straw & White \\
\hline KDK & & Wetland & 6.2 & Medium & Waxy & Straw + purple tint & Purple \\
\hline KHCMU & & Upland & 5.9 & Medium & Waxy & Straw + purple tint & Purple \\
\hline
\end{tabular}

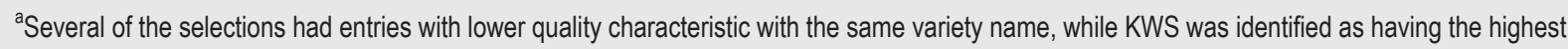
Fe and phenols.

bBrown rice: length—extra-long (>7.50 mm), long $(6.61-7.50 \mathrm{~mm})$, medium $(5.51-6.50 \mathrm{~mm})$ and short $(<5.50 \mathrm{~mm})$; shape by length-to-width ratio: slender (>3), medium (2-3) and bold (1-2) (Juliano, 1993).

${ }^{\circ}$ Waxy or glutinous ( $\leq 10 \%$ amylose); non-waxy or non-glutinous (>10\% amylose).

with purple tint, to straw colour with no pigmentation. The non-glutinous Bue Bang (BB) and Bue Tor Na (BTN) both had straw coloured hull and white pericarp.

The Fe concentration averaged higher, but $\mathrm{Zn}$ was in the same range as the mega-variety checks KDML105 and RD6 (Table 2). Anthocyanin concentration also averaged significantly higher than the purple rice checks, Kam Doisaket (KDK) and Kam Hom Chiang Mai University (KHCMU), although phenols and anti-oxidative capacity did not. Neither the plant ecotype (upland vs. wetland) nor the grain starch (glutinous vs. non-glutinous) and pigmentation type were differentiated by their $\mathrm{Fe}$ and $\mathrm{Zn}$ contents. Entries of the wetland and upland ecotype were not significantly different in anthocyanin content and anti-oxidative capacity, although higher phenol levels were found among the wetland entries. Glutinous rice entries were significantly higher than non-glutinous entries in anthocyanin and phenolic contents as well as anti-oxidative capacity. Purple rice had significantly higher anthocyanin and phenolic content, and anti-oxidative capacity than entries that were without pigmentation or mixtures with nonpigmented, red and purple pericarps. The selected materials also exhibited different agronomic characteristics from the lowland checks when grown together at a highland site in Mae Wang (Table 4). The selected lines were generally earlier and shorter in stature compared with the lowland check varieties. Three of the nine selected lines, namely Kam Wiang Sa (KWS), Bian koo (BK) and Kao Saeng (KS), yielded in the range as the lowland checks, while the rest yielded significantly less as was the highland check KHCMU. Regression analysis showed that there was no association between the number of panicles and grain yield $\left(R^{2}=-0.32\right.$, NS at $\left.P>0.05\right)$.

Nutritional and bioactive qualities of the selected entries were found to vary when grown at three different locations (Table 5). All quality characteristics of individual entries were lower when grown at Mae Wang and CMU than in farmers' fields, except that the $\mathrm{Zn}$ and phenolic contents were uniform among the three locations. KWS and BK had the highest Fe content in rice grain among on-farm samples, with Fe contents of 14.3 and $14.2 \mathrm{mg} \mathrm{kg}^{-1}$, respectively, but these were only half those at Mae Wang and CMU, in the same range as the check varieties, KDML105 and RD6. Two selected lines with high grain Zn, BTN and $\mathrm{BB}$, had grain $\mathrm{Zn}$ at 28.5 and $28.1 \mathrm{mg} \mathrm{kg}^{-1}$, and were slightly higher in grain $\mathrm{Zn}$ only when grown at Mae Wang. The highest levels of phenols among on-farm samples were found in KWS and KS at 346.0 and $336.7 \mathrm{mg}$ gallic acid equivalent (gae) $100 \mathrm{~g}^{-1}$, respectively. KWS produced uniformly high phenolic content among the three locations, while KS produced slightly higher phenolic content at Mae Wang and substantially higher at CMU. Anthocyanin was highest in rice from the farmer's field, at $166.4 \mathrm{mg}$

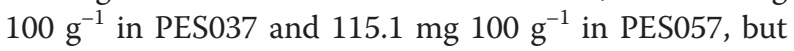
only a fraction of these when grown at Mae Wang and CMU. Similarly, anti-oxidative capacities were higher in the rice grown in the farmer's fields, with entries DMO and KAK having 1811.5 and $1806.9 \mathrm{mg}$ Trolox100 $\mathrm{g}^{-1}$, 
Table 4. Agronomic parameters of selected rice varieties from the highlands compared with check varieties grown at Mae Wang, a highland site in Northern Thailand.

\begin{tabular}{lcccc} 
Variety & Days to flowering & Plant height $(\mathbf{c m})$ & Panicles/hill & Grain yield (t ha $\left.{ }^{-1}\right)$ \\
\hline PES037 & $83 \pm 5^{\text {a }}$ & $94 \pm 9$ & $6 \pm 2$ & $1.83 \pm 0.10$ \\
PES057 & $81 \pm 6$ & $94 \pm 11$ & $5 \pm 2$ & $2.30 \pm 0.05$ \\
BB & $92 \pm 3$ & $96 \pm 12$ & $7 \pm 3$ & $2.13 \pm 0.07$ \\
BTN & $98 \pm 2$ & $75 \pm 13$ & $7 \pm 2$ & $1.85 \pm 0.06$ \\
DMO & $89 \pm 5$ & $73 \pm 8$ & $5 \pm 2$ & $2.10 \pm 0.04$ \\
KAK & $98 \pm 2$ & $102 \pm 15$ & $3 \pm 1$ & $2.11 \pm 0.05$ \\
KWS & $106 \pm 4$ & $130 \pm 10$ & $5 \pm 2$ & $2.79 \pm 0.05$ \\
BK & $99 \pm 1$ & $113 \pm 10$ & $3 \pm 1$ & $2.72 \pm 0.07$ \\
KS & $100 \pm 2$ & $111 \pm 8$ & $3 \pm 2$ & $2.45 \pm 0.04$ \\
Check variety & $114 \pm 4$ & $152 \pm 10$ & & \\
KDML105 & $115 \pm 1$ & $139 \pm 8$ & $5 \pm 1$ & $2.57 \pm 0.03$ \\
RD6 & $118 \pm 1$ & $125 \pm 10$ & $4 \pm 1$ & $2.65 \pm 0.04$ \\
KDK & $85 \pm 2$ & $94 \pm 6$ & $3 \pm 1$ & $2.63 \pm 0.03$ \\
KHCMU & & & $3 \pm 1$ & $2.08 \pm 0.04$ \\
\hline
\end{tabular}

${ }^{\text {a }}$ Standard deviation.

Table 5. Variation in grain quality of farmers' selected rice seed samples grown at three locations in Northern Thailand.

\begin{tabular}{|c|c|c|c|c|}
\hline \multirow[t]{2}{*}{ Selected for } & \multirow[t]{2}{*}{ Variety name } & \multicolumn{2}{|c|}{ Highland } & \multirow{2}{*}{$\begin{array}{c}\text { Lowland } \\
\mathrm{CMU}\end{array}$} \\
\hline & & Farmer's fields & Mae Wang & \\
\hline \multirow[t]{2}{*}{ Iron $\left(\mathrm{mg} \mathrm{Fe} \mathrm{kg}^{-1}\right)$} & KWS & $14.3 \pm 1.0^{\mathrm{a}}$ & $8.6 \pm 0.3$ & $6.8 \pm 1.4$ \\
\hline & BK & $14.2 \pm 0.0$ & $7.2 \pm 0.1$ & $7.5 \pm 1.1$ \\
\hline \multirow[t]{2}{*}{ Zinc $\left(m g\right.$ Zn kg $\left.{ }^{-1}\right)$} & BTN & $28.5 \pm 0.1$ & $36.4 \pm 2.1$ & $27.1 \pm 4.8$ \\
\hline & BB & $28.1 \pm 0.6$ & $34.8 \pm 0.5$ & $30.5 \pm 4.8$ \\
\hline \multirow[t]{2}{*}{ Phenols(mg gae $100 \mathrm{~g}^{-1}$ ) } & KWS & $346.0 \pm 2.3$ & $334.7 \pm 18.4$ & $323.0 \pm 46.2$ \\
\hline & KS & $336.7 \pm 3.7$ & $363.4 \pm 0.5$ & $439.0 \pm 112.1$ \\
\hline \multirow[t]{2}{*}{ Anthocyanin (mg $100 \mathrm{~g}^{-1}$ ) } & PES037 & $166.4 \pm 12.6$ & $40.3 \pm 1.8$ & $22.5 \pm 7.6$ \\
\hline & PES057 & $115.1 \pm 7.0$ & $70.9 \pm 1.0$ & $18.5 \pm 5.7$ \\
\hline \multirow{2}{*}{$\begin{array}{l}\text { Anti-oxidative capacity } \\
\left(\mathrm{mg} \text { Trolox100 } \mathrm{g}^{-1)}\right.\end{array}$} & DMO & $1811.5 \pm 16.5$ & $580.0 \pm 14.1$ & $524.0 \pm 173.3$ \\
\hline & KAK & $1806.9 \pm 3.9$ & $449.2 \pm 5.6$ & $541.0 \pm 213.4$ \\
\hline \multicolumn{5}{|l|}{ Check variety } \\
\hline \multirow[t]{2}{*}{ Iron (mg Fe kg $\left.{ }^{-1}\right)$} & KDML105 & & $6.8 \pm 0.8$ & $6.8 \pm 0.1$ \\
\hline & RD6 & & $6.3 \pm 0.7$ & $6.3 \pm 1.0$ \\
\hline \multirow[t]{2}{*}{ Zinc (mg Zn kg $\left.{ }^{-1}\right)$} & KDML105 & & $22.0 \pm 0.8$ & $22.0 \pm 0.8$ \\
\hline & RD6 & & $23.4 \pm 0.0$ & $23.4 \pm 0.0$ \\
\hline \multirow[t]{2}{*}{ Phenols(mg gae $100 \mathrm{~g}^{-1}$ ) } & KDK & & $337.8 \pm 0.0$ & $283.5 \pm 2.2$ \\
\hline & KHCMU & & $336.8 \pm 4.9$ & $302.3 \pm 0.6$ \\
\hline \multirow[t]{2}{*}{ Anthocyanin (mg $100 \mathrm{~g}^{-1}$ ) } & KDK & & $25.6 \pm 2.2$ & $25.6 \pm 2.2$ \\
\hline & KHCMU & & $29.8 \pm 0.1$ & $29.8 \pm 0.1$ \\
\hline \multirow{2}{*}{$\begin{array}{l}\text { Anti-oxidative capacity } \\
\text { (mg Trolox100 g }\end{array}$} & KDK & & $303.1 \pm 3.3$ & $242.1 \pm 29.3$ \\
\hline & KHCMU & & $386.5 \pm 28.8$ & $269.7 \pm 3.0$ \\
\hline
\end{tabular}




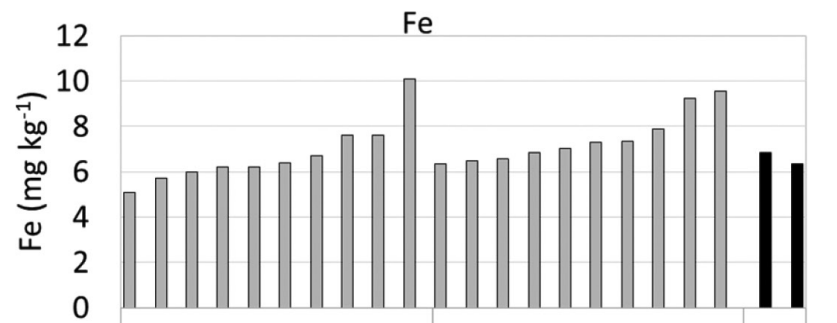

123456789101234567891012 KWS (20.8\%) BK (15.1\%)

Anthocyanin

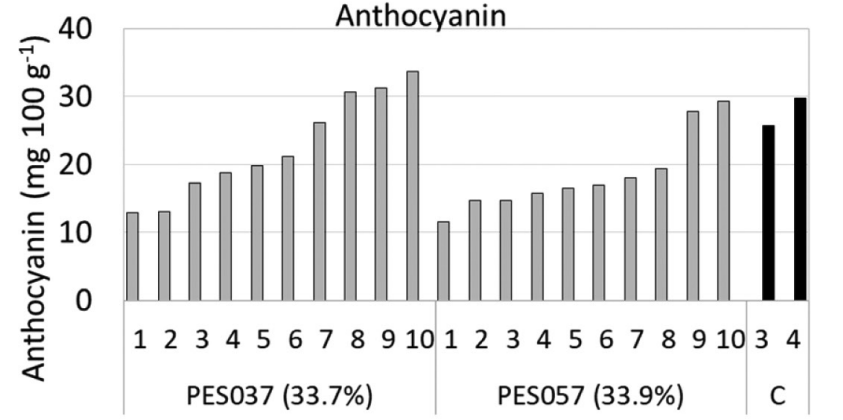

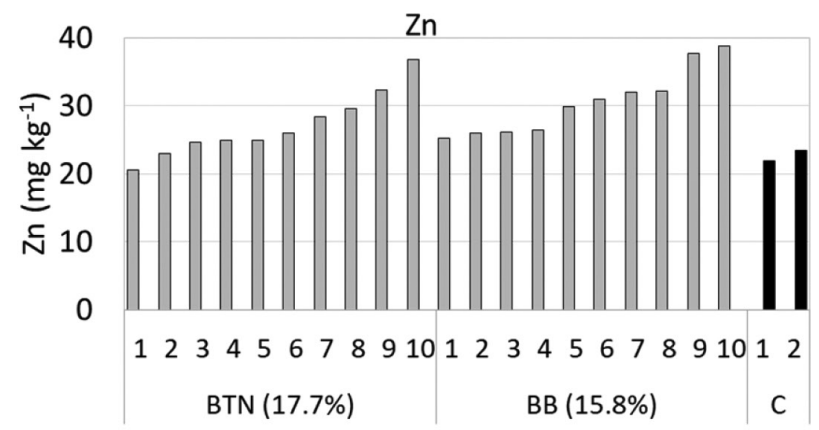

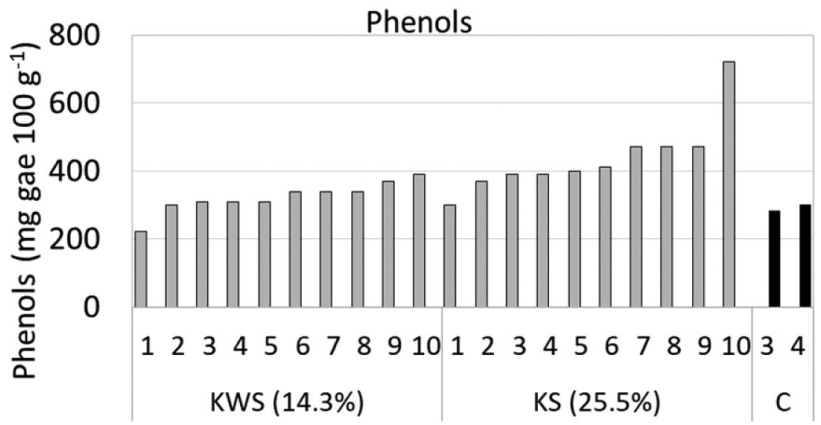

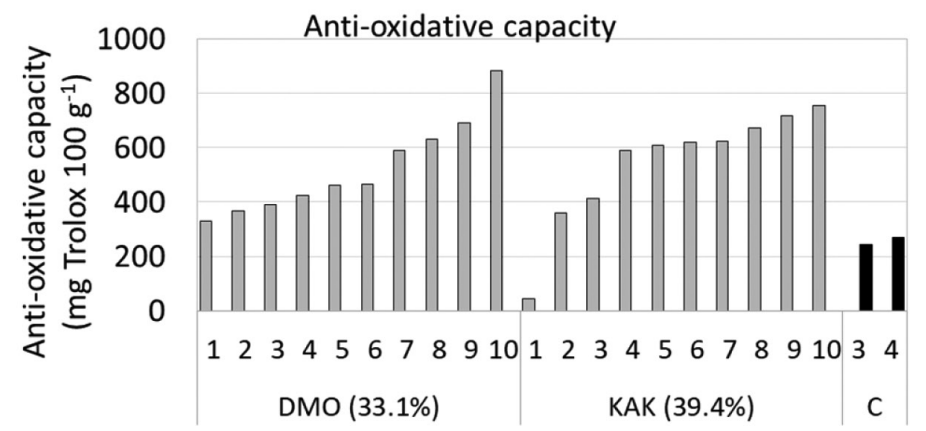

Figure 3. Variation in grain quality among 10 single seed decent lines from selected farmers' rice seed from Northern Thailand (in brackets after variety name is coefficient of variation for the sample; $C=$ check, $1=\mathrm{KDML} 105 ; 2=\mathrm{RD} 6 ; 3=\mathrm{KDK} ; 4=\mathrm{KHCMU}$ ).

respectively, and were lower by $1 / 3$ when the entries were grown at Mae Wang and CMU. Substantial variation in nutritional and bioactive qualities was found among plants within the selected lines grown together at CMU (Figure 3). Individual plants with exceptional quality were identified, which exceeded the level in the higher check by up to $48 \%$ for Fe, $65 \%$ for $\mathrm{Zn}, 138 \%$ for phenols and $239 \%$ for anti-oxidative capacity. Anthocyanin concentration was also variable among individual plants of the same selected entry, but plants with higher concentration than the check varieties KDK and KHCMU were rare.

\section{Discussion}

In spite of the replacement of local rice varieties by modern high-yielding varieties that have been reported across the world's rice growing regions (Cheng et al., 2007; Dalrymple, 1986; Rerkasem and Rerkasem, 2002), the highlands of Northern Thailand is one of the few places where local rice varieties are still to be found (Jamjod et al., 2017). This present study has shown that considerable variation in grain quality characteristics with health benefits existed in local rice varieties which are grown on-farm in Northern Thailand at the time this study was conducted. The rice with exceptional grain quality therefore provides the farm families with other health benefits in addition to dietary energy. Environmental constraints and limited access to modern varieties contribute to the use of locally adapted rice varieties grown with minimal inputs. Farmers continue grow these local rice varieties with seed kept from the previous season or through exchanging their seeds with other farmers (Oupkaew et al., 2011; Sirabanchongkran et al., 2004). The local rice varieties with top quality characteristics in this study contained twice the Fe and Zn of mega-varieties, KDML105 and RD6, while 
anthocyanin and anti-oxidative capacity were more than double the standard check varieties, KDK and KHCMU. This highlights the direct benefits of rice with high nutritional and bioactive quality to the farm families that grow it. It has been previously suggested that high seed $\mathrm{Zn}$ would be beneficial to germination and early growth in upland rice in $\mathrm{Zn}$-deficient soils exacerbated by the ash from the slash and burn practice (Jaksomsak et al., 2015). Ranking of the local varieties based on grain quality characteristics in this study has also shown that quality characteristics with health implication varied widely among local varieties distributed across the highlands of Northern Thailand. KDML105 and RD6, the check varieties for Fe and $\mathrm{Zn}$, are among Thailand's mega rice varieties that are generally low in these nutrients (Saenchai et al., 2012). The marginally higher Fe and $\mathrm{Zn}$ in BB and $\mathrm{BTN}$, the only white rice varieties which are grown for home consumption among the selected samples, would therefore directly benefit those farm families that produced the rice for their own use. However, as a source of high $\mathrm{Fe}$ and $\mathrm{Zn}$ traits, genotypes with much higher concentration of the nutrients have been identified in previous studies on local rice germplasm in Thailand (Jaksomsak et al., 2015; Pintasen et al., 2007). The potential for development of rice varieties with special quality for the highlands is suggested by the identification of local rice varieties with exceptional levels of anthocyanin, phenols and anti-oxidative capacity.

Variation in the rice grain quality by location (Table 5) indicated a degree of instability of individual characteristics. Iron and $\mathrm{Zn}$ concentrations in the rice grain can be influenced by climatic and soil factors (Gregorio et al., 2000; Prasad et al., 2014). Zinc is primarily dependent on the native soil $\mathrm{Zn}$, in which the grain $\mathrm{Zn}$ of a single rice genotype was reported to range from 8 to $47 \mathrm{mg} \mathrm{Zn} \mathrm{kg}^{-1}$ (Wissuwa et al., 2008). On the other hand, the grain $\mathrm{Zn}$ in some local rice varieties was shown to be lowered by the dilution effect of higher yield brought about by the application of nitrogen fertiliser (Jaksomsak et al., 2017). In the case of bioactive compounds and anti-oxidative capacity, strong genotype by environment (GxE) effects have been demonstrated in few studies in which the performance of the rice genotypes was evaluated under different environmental conditions (e.g. Banterng and Joralee, 2015; Somsana et al., 2013). Genotypes may respond differently to the different conditions. For example, increasing $\mathrm{N}$ supply depressed anthocyanin content in one purple rice genotype but increased it in another (Kathuai et al., 2013). Some pigmented rice genotypes grown in a farmer's field in the highland (elevation $800 \mathrm{~m}$ ) had higher anthocyanin concentration and antioxidative capacity than when it was grown in the lowland (elevation $330 \mathrm{~m}$ ) at CMU; however, for other genotypes, the reverse was true (Rerkasem et al., 2015). Among the bioactive components, phenol concentration was the most stable across locations, while the anthocyanin and anti-oxidative capacity of rice grown in the on-farm trial at Mae Wang were only one quarter of those produced on the original location, thus clearly indicating the location specificity of these quality attributes of the pigmented rice. The rice samples with the highest anti-oxidative capacity, of the varieties DMO and KAK, were grown at an exceptionally high elevation of $1031 \mathrm{~m}$ (for the highlands of Thailand), in Wawi, Chiang Rai. The samples with the highest anthocyanin concentration, however, were grown at a village close to the on-farm trial at Mae Wang $\left(0.05^{\circ}\right.$ to the south, $0.03^{\circ}$ to the west $)$, but at $200 \mathrm{~m}$ higher elevation. Confirmation and reproducibility of the exceptional quality features of the rice grown, even without definitive identification of the responsible factors, would enable some of these highland villages to benefit from the legal protection provided by the geographical indication (GI), within Thailand (Department of Intellectual Property [DIP], 2003) and internationally (World Intellectual Property Oganization [WIPO], 2019), as has been the case of special-quality rice from the south, Sangyod Muang Phattalung (DIP, 2006), and north-east, Hom Mali Thung Kula Rong-hai (DIP, 2007), of Thailand. While some selected rice varieties were comparable in productivity to the check varieties, most others were much lower yielding. However, a well-developed market for premium-priced special-quality rice has enabled farmers in Thailand (Rerkasem, 2017) and also in Cambodia (International Finance Corporation [IFC], 2015; Vannak, 2017; Vent et al., 2015) to compensate for their inability to take advantage of modern rice varieties with higher yield by growing local varieties with higher quality and price.

When grown at CMU in the lowland $(330 \mathrm{~m})$, the farmers' rice varieties maintained their higher phenol concentration and anti-oxidative capacity than the check varieties, although not in the anthocyanin concentration. Genetic diversity within the farmers' seed lots is a common feature of local rice varieties in Thailand, and has been demonstrated with molecular markers (Pusadee et al., 2009, 2014) and in functional traits (Jaksomsak et al., 2015; Laenoi et al., 2018; Pintasen et al., 2007). The variation in the grain quality characteristics of the 10 single seed descent lines from each sample, that is, the rice grown from individual seeds found here (Figure 3), demonstrates the range of bioactive components in the on-farm germplasm that were averaged out in the chemical analyses involving samples each containing 50-100 rice kernels. Intensity of staining, Perls' Prussian blue specific for $\mathrm{Fe}$ and dithizone specific for $\mathrm{Zn}$ have been suggested as a means for rapidly detecting variation in the concentration of these nutrients in individual rice grains (Jaksomsak et al., 2015; Pintasen et al., 2007). Visual ranking of the intensity of the purple pigmentation of the pericarp correlated significantly with anthocyanin 
concentration (Kathuai et al., 2013), but unfortunately no similar quick and easy method for preliminary screening is available for phenols and anti-oxidative capacity. The close association between anthocyanin concentration and anti-oxidative capacity previously reported (e.g. Nam et al., 2006; Rerkasem et al., 2015; Xiongsiyee et al., 2018) is also found here with the single seed descent lines $\left(R^{2}=0.61, P<0.001\right)$.

Enhancing the nutritional quality of staple food crops is a powerful tool to increase the daily intake of nutritional compounds to combat malnutrition and afford better health. Breeding rice varieties with high grain nutritional quality is a sustainable solution that benefits consumers as well as farmers (Graham et al., 1999; Welch and Graham, 2004). However, improvement in grain quality of pigmented rice needs to be considered separately from that of the ordinary white rice normally consumed as staple food. Pigmented rice has long been part of the Asian rice culture (Appa et al., 2006; Sukhonthara et al., 2009). Pigmented rice has been reported to have much lower genetic diversity and higher homozygosity (Pusadee et al., 2019; Vilayheuang et al., 2016) compared with the local germplasm of ordinary white rice (Huang et al., 2010; Pusadee et al., 2009, 2014; Roy et al., 2016; Wunna et al., 2016), possibly due to the more conservative management of a small area of the crop $(<5 \%$ of the total rice area) for special usages in making ceremonial preparation and desserts. In spite of this, there is clear evidence of variation in functional traits in the range of anthocyanin, phenols and anti-oxidative capacity found in this study among the 10 single-seed decent lines of each of the selected farmer's rice seed stock. The top-performing lines for the bioactive compounds are being further investigated for potential development of single genotypes. Alternatively, quality could be raised by elimination of the lower performing lines. It should, however, be pointed out that grain quality improvement in pigmented rice is unlikely to directly benefit the majority of rice consumers as it is not regularly used as the staple food. The economic potential of pigmented rice lies in the emerging market for premium-priced special-quality rice as health food and supplements (e.g. see Boonsit et al., 2010; Panomjan et al., 2016; Pusadee et al., 2019; Saeton, 2010).

\section{Conclusions}

In conclusion, a wide range of variation in grain nutritional and bioactive quality was found among the local rice varieties grown in different locations in the highlands of Northern Thailand. Strong location effects were observed on the selected genotypes in their anthocyanin content and anti-oxidative capacity, but not their phenol content. Variation was also found in the grain nutritional and bioactive quality among single-seed descent lines of each of the selected farmer's seed -lots. With respect to bioactive compounds, potential for development of pigmented rice with improved grain quality may be found in further investigation of the top-performing lines or elimination of the inferior lines.

\section{Acknowledgements}

The authors would like to thank the farmers for generously sharing seed and information.

\section{Conflict of interest}

The authors have declared no conflict of interest in this article.

\section{Compliance with ethical standards}

This article followed all ethical standards for a research without direct contact with human or animal subjects.

\section{Funding}

This research was supported by the Thailand Research Fund and Chiang Mai University. The first author is a recipient of a Royal Golden Jubilee PhD scholarship (PHD/0348/2551).

\section{References}

Allan, J.E., 1961. The determination of zinc in agricultural materials by atomic-absorption spectrophotometry. Analyst 86: 530-534. https://doi.org/10.1039/an9618600530

Appa, R.S., Schiller, J.M., Bounphanousay, C., Inthapanya, P. and Jackson, M.T., 2006. The colored pericarp (black) rice of Laos. In: Schiller, J.M., Chanphengxay, M.B., Linquist, B. and Appa, R.S. (eds.) Rice in Laos. International Rice Research Institute, Manila, Philippines, pp. 175-186.

Banterng, P. and Joralee, A., 2015. Evaluation of black glutinous rice genotypes for stability of gamma oryzanol and yield in tropical environments. Turkish Journal of Field Crops 20(2): 142-149. https://doi.org/10.17557/tjfc.45719

Black, M.M., 1998. Zinc deficiency and child development. American Journal of Clinical Nutrition 68: 464S-469S. https:// doi.org/10.1093/ajcn/68.2.464S

Boonsit, P., Pongpiachan, P., Julsrigival, S. and Karladee, D., 2010. Gamma oryzanol content in glutinous purple rice landrace varieties. Chiang Mai University Journal of the Natural Science 9(1): 151-157.

Boue, S.M., Daigle, K.W., Chen, M.H., Cao, H. and Heiman, M.L., 2016. Antidiabetic potential of purple and red rice (Oryza sativa L.) bran extracts. Journal of Agriculture and Food Chemistry 64: 5345-5353. https://doi.org/10.1021/acs.jafc.6b01909

Cakmak, I., 2000. Possible roles of zinc in protecting plant cells from damage by reactive oxygen species. New Phytologist 146: 185-205. https://doi.org/10.1046/j.1469-8137.2000.00630.x 
Cheng, S.H., Zhuang, J.Y., Fan, Y.Y., Du, J.H. and Cao, L.Y., 2007. Progress in research and development on hybrid rice: a superdomesticate in China. Annals of Botany 100: 959-966. https:// doi.org/10.1093/aob/mcm121

Dalrymple, D.G., 1986. Development and spread of high-yielding rice varieties in developing countries. Bureau for Science and Technology, Agency for International Development, Washington, DC, US, pp. 37-90.

Demirbas, A., 2005. $\beta$-glucan and mineral nutrient contents of cereals grown in Turkey. Food Chemistry 90: 773-777. https://doi. org/10.1016/j.foodchem.2004.06.003

Department of Intellectual Property (DIP), 2003. Geographical Indication (GI). Department of Intellectual Property, Ministry of Commerce, Government of Thailand, Royal Gazette, BE 2546, Bangkok, Thailand, 20th October 2003.

Department of Intellectual Property (DIP), 2006. Sangyod Muang Phattalung SC 49100019. Geographical Indication (GI) announcement. Department of Intellectual Property, Ministry of Commerce, Government of Thailand, Bangkok, Thailand.

Department of Intellectual Property (DIP), 2007. Hom Mali Thung Kula Rong-hai SC 50100022. Geographical Indication (GI) announcement, Department of Intellectual Property, Ministry of Commerce, Government of Thailand, Bangkok, Thailand.

Escribano-Bailón, M.T., Santos-Buelga, C. and Rivas-Gonzalo, J.C., 2004. Anthocyanins in cereals. Journal of Chromatography A 1054: 129-141. https://doi.org/10.1016/j.chroma.2004.08.152

Folin, O. and Denis, W., 1912. On phosphotungstic-phosphomolybdic compounds as color reagents. Journal of Biology and Chemistry 12: 239-243.

Graham, R., Senadhira, D., Beebe, S., Iglesias, C. and Monasterio, I., 1999. Breeding for micronutrient density in edible portions of staple food crops: conventional approaches. Field Crops Research 60: 57-80. https://doi.org/10.1016/S0378-4290(98)00133-6

Gregorio, G.B., Senadhira, D., Htut, H. and Graham, R.D., 2000. Breeding for trace mineral density in rice. Food and Nutrition Bulletin 21(4): 382-386.

Harlan, J.R., 1992. Crops and man, $2^{\text {nd }}$ edition. American Society of Agronomy, Madison, WI, USA, pp. 193-213.

Huang, X., Wei, X., Sang, T., Zhao, Q., Feng, Q., Zhao, Y., Li, C., Zhu, C., Lu, T., Zhang, Z., Li, M., Fan, D., Guo, Y., Wang, A., Wang, L., Deng, L., Li, W., Lu, Y., Weng, Q., Liu, K., Huang, T., Zhou, T., Jing, Y., Li, W., Lin, Z., Buckler, E.S., Qian, Q., Zhang, Q.F., Li, J. and Han, B., 2010. Genome-wide association studies of 14 agronomic traits in rice landraces. Nature Genetics 42(11): 961-967. https://doi.org/10.1038/ng.695

International Finance Corporation (IFC), 2015. Cambodia rice export potential and strategies. International Finance Corporation, Cambodia Agribusiness Series Number 4. IFC, Phnom Penh, Cambodia, pp. 3-17.

Jaksomsak, P., Rerkasem, B. and Prom-u-thai, C., 2017. Responses of grain zinc and nitrogen concentration to nitrogen fertilizer application in rice varieties with high-yielding low-grain zinc and low-yielding high grain zinc concentration. Plant and Soil 411: 101-109. https://doi.org/10.1007/s11104-016-3056-1

Jaksomsak, P., Yimyam, N., Dell, B., Prom-u-thai, C. and Rerkasem, B., 2015. Variation of seed zinc in a local upland rice germplasm from Thailand. Plant Genetics Resouruces 13(2): 168-175. https://doi.org/10.1017/S1479262114000872

Jamjod, S., Yimyam, N., Lordkaew, S., Prom-u-thai, C. and Rerkasem, B., 2017. Characterization of on-farm rice germplasm in an area of the crop's center of diversity. Chiang Mai University Journal of the Natural Science 16(2): 85-98. https://doi.org/10.12982/ cmujns.2017.0007

Juliano, B.O., 1971. A simplified assay for milled-rice amylose. Cereal Science Today 16(11): 334-340.

Juliano, B.O., 1993. Rice in human nutrition. Food and Agriculture Organization of The United Nations, Rome, Italy, pp. 37-38.

Kathuai, W., Rerkasem, B., Jamjod, S., Phatarakul, N. and Prom-uthai, C., 2013. Effects of nitrogen and water managements on yield and anthocyanin content in two purple glutinous rice varieties. Khon Kaen Agriculture Journal 41(4): 403-410. (In Thai with English abstract)

Keen, C.L. and Gershwin, M.E., 1990. Zinc deficiency and immune function. Annual Reviews of Nutririon 10: 415-431. https://doi. org/10.1146/annurev.nu.10.070190.002215

Kehrer, J.P., 1993. Free radicals as mediators of tissue injury and disease. Critical Reviews in Toxicology 23(1): 21-48. https://doi. org/10.3109/104.0844.9309104073

Kumar, R., Malaiya, S. and Srivastava, M.N., 2004. Evaluation of morphophysiological traits associated with drought tolerance in rice. Indian Journal of Plant Physiology 9(3): 305-307.

Kutman, B., Yildiz, B., Ozturk, L. and Cakmak, I., 2010. Biofortification of durum wheat with zinc through soil and foliar applications of nitrogen. Cereal Chemistry 87: 1-9. https://doi. org/10.1094/CCHEM-87-1-0001

Laenoi, S., Phattarakul, N., Jamjod, S., Yimyam, N., Dell, B. and Rerkasem, B., 2015. Genotypic variation in adaptation to soil acidity in local upland rice varieties. Plant Genettic Resources 13(3): 206-212. https://doi.org/10.1017/S1479262114000896

Laenoi, S., Rerkasem, B., Lordkaew, S. and Prom-u-thai, C., 2018. Seasonal variation in grain yield and quality in different rice varieties. Field Crops Research 221: 350-357.

Lozoff, B. and Georgieff, M.K., 2006. Iron deficiency and brain development. Seminar in Pediatric Neurology Journal 13: 158-165. https://doi.org/10.1016/j.spen.2006.08.004

Nam, S.H., Choi, S.P., Kang, M.Y., Koh, H.J., Kozukue, N. and Friedman, M., 2006. Antioxidative activities of bran extracts from twenty one pigmented rice cultivars. Food Chemistry 94: 613-620.

Naruebal, S., 2009. Varietal diversity of highland rice Bue Polo variety in Maehong Son province. Master thesis (Geosocial Based Sustainable Development), Graduate School, Maejo University, Bangkok (In Thai)

Oupkaew, P., Pusadee, T., Sirabanchongkran, A., Rerkasem, K., Jamjod, S. and Rerkasem, B., 2011. Complexity and adaptability of a traditional agricultural system: case study of a gall midge resistant rice landrace from northern Thailand. Genetic Resources and Crop Evolution 58: 361-372. https://doi.org/10.1007/ s10722-010-9579-Z

Panomjan, N., Jamjod, S., Rerkasem, B., Dell, B. and Prom-u-thai, C., 2016. Variation in seed morphology of Sang Yod rice variety from southern Thailand. Khon Kaen Agriculture Journal 44(1): 83-94. (In Thai with English abstract). 
Pintasen, S., Prom-u-thai, C., Jamjod, S., Yimyam, N. and Rerkasem, B., 2007. Variation of grain iron content in a local upland rice germplasm from the village of Huai Tee Cha in northern Thailand. Euphytica 158: 27-34. https://doi.org/10.1007/s10681-007-9421-7

Prasad, R., Shivay, Y.S. and Kumar, D., 2014. Agronomic biofortification of cereal grains with iron and zinc. In: Sparks. D.L. (ed.), Advances in Agronomy, 125, Academic Press, Burlington, pp. 55-91.

Prom-u-thai, C. and Rerkasem, B., 2001. Grain iron concentration in Thai rice germplasm. In: Horst, W.J., Schenk, M.K., Bürkert, A., Claassen, N., Flessa, H., Frommer, W.B., Goldbach, H., Olfs, H.W., Römheld, V., Sattelmacher, B., Schmidhalter, U., Schubert, S., Wirén, N.V. and Wittenmayer, L. (eds.) Plant nutrition. Developments in plant and soil sciences volume 92. Kluwer Academic, Dordrecht, Netherlands, pp. 350-351.

Pusadee, T., Jamjod, S., Chiang, Y.C., Rerkasem, B. and Schaal, B.A., 2009. Genetic structure and isolation by distance in a landrace of Thai rice. Proceedings of the National Academy of Science 106(33): 13880-13885. https://doi.org/10.1073/pnas.0906720106

Pusadee, T., Oupkaew, P., Rerkasem, B., Jamjod, S. and Schaal, B.A., 2014. Natural and human-mediated selection in a landrace of Thai rice (Oryza sativa). Annal of Applied Biology 165: 280-292.

Pusadee, T., Wongtamee, A., Rerkasem, B., Olsen, K.M. and Jamjod, S., 2019. Farmers drive genetic diversity of Thai purple rice (Oryza sativa L.) landraces. Economics Botany 73(1): 76-85. https://doi. org/10.1007/s12231-018-9436-0

Rerkasem, B., 2017. The rice value chain: a case study of Thai rice. Chiang Mai University Journal of Social Sciences and Humanities 4(1): 1-26. https://doi.org/10.12982/CMUJASR.2017.0001

Rerkasem, B., Jumrus, S., Yimyam, N. and Prom-u-thai, C., 2015. Variation of grain nutritional quality among Thai purple rice genotypes grown at two different altitudes. ScienceAsia 41: 337-385. https://doi.org/10.2306/scienceasia1513-1874.2015.41.377

Rerkasem, B. and Rerkasem, K., 2002. Agrodiversity for in situ conservation of Thailand's native rice germplasm. Chiang Mai University Journal of the Natural Science 1(2): 129-148.

Roy, S., Marndi, B.C., Mawkhlieng, B., Banerjee, A., Yadav, R.M., Misra, A.K. and Bansal, K.C., 2016. Genetic diversity and structure in hill rice (Oryza sativa L.) landraces from the north-eastern Himalayas of India. BMC Genetics 17: 107.

Saenchai, C., Prom-u-thai, C., Jamjod, S., Dell, B. and Rerkasem, B., 2012. Genotypic variation in milling depression of iron and zinc concentration in rice grain. Plant and Soil 361: 271-278. https:// doi.org/10.1007/s11104-012-1228-1

Saeton, S., 2010. Local rice varieties of southern Thailand volume II. Patthalung Rice Research Center. Bureau of Rice Research and Development, Rice Department, Bangkok, Thailand, pp. 16-17. (In Thai)

Sirabanchongkran, A., Yimyam, N., Boonma, W., Rerkasem, K., Coffey, K., Pinedo-Vasquez, M. and Padoch, C., 2004. Varietal turnover and seed exchange: implications for conservation of rice genetic diversity on-farm. International Rice Research Notes 29: 18-20.

Somsana, P., Wattana, P., Suriharn, B. and Sanitchon, J., 2013. Stability and genotype by environment interactions for grain anthocyanin content of Thai black glutinous upland rice (Oryza sativa). SABRAO Journal Breeding Genetics 45(3): 523-532.

Sukhonthara, S., Theerakulkait, C. and Miyazawa, M., 2009. Characterization of volatile aroma compounds from red and black rice bran. Journal of Oleo Science 58(3): 155-161. https:// doi.org/10.5650/jos.58.155

Vannak,C.,2017.Cambodian riceamong theworld's best three.Khmer Times November 9,2017. Availableat: https://www.khmertimeskh. com/5089690/cambodian-rice-among-worlds-best-three/.

Vent, O., Koma, Y.S., Levine, C. and Uphoff, N., 2015. Market incentives for ecofriendly SRI rice production in Cambodia. In: Sewadeh, M. and Jaffee, S. (eds.) Shades of green multi-stakeholder initiatives to reduce the environmental footprint of commercial agriculture. EcoAgriculture Partners, Washington, DC, USA, pp. 73-80.

Vilayheuang, K., Machida-Hirano, R., Bounphanousay, C. and Watanabe, K.N., 2016. Genetic diversity and population structure of 'Khao Kai Noi', a Lao rice (Oryza sativa L.) landrace, revealed by microsatellite DNA markers. Breeding Sciences 66(2): 204-212. https://doi.org/10.1270/jsbbs.66.204.

Welch, R.M. and Graham, R.D., 2004. Breeding for micronutrients in staple food crops from a human nutrition perspective. Journal of Experimental Botany 55: 353-364.

White, P.J. and Broadley, M.R., 2005. Biofortifying crops with essential mineral elements. Trends in Plant Science 10(12): 586-593. https://doi.org/10.1016/j.tplants.2005.10.001

World Intellectual Property Oganization (WIPO), 2019. Geographical Indications (GI). World Intellectual Property Oganization. Available at https://www.wipo.int/geo_indications/en/.

Wissuwa, M. and Ae, N., 2001. Genotypic variation for tolerance to phosphorus deficiency in rice and the potential for its exploitation in rice improvement. Plant Breeding 120: 43-48. https://doi. org/10.1046/j.1439-0523.2001.00561.x

Wissuwa, M., Ismail, A.M. and Graham, R.D., 2008. Rice grain zinc concentrations as affected by genotype, native soil-zinc availability, and zinc fertilization. Plant and Soil 306: 37-48.

Wrolstad, R.E., Acree, T.E., An, H., Decker, E.A., Penner, M.H., Reid, D.S., Schwartz, S.J., Shoemaker, C.F., Smith, D.M. and Sporns, P., 2001. Current protocols in food analytical chemistry. Wiley, New York, NY, USA, pp. F1.2.1-F1.2.13.

Wunna, K.N., Ohsawa, R., Obara, M., Yanagihara, S., Aung, P.P. and Fukuta, Y., 2016. Genetic variation of rice (Oryza sativa L.) germplasm in Myanmar based on genomic compositions of DNA markers. Breeding Sciences 66(5): 762-767.

Xiongsiyee, V., Rerkasem, B., Veeradittakit, J., Saenchai, C., Lordkaew, S. and Prom-u-thai, C.T., 2018. Variation in grain quality of upland rice from Luang Prabang province, Lao PDR. Rice Science 25(2): 94-102. https://doi.org/10.1016/j. rsci.2018.02.002

Yue, X. and $\mathrm{Xu}, \mathrm{Z}$., 2008. Changes of anthocyanins, anthocyanidins, and antioxidant activity in bilberry extract during dry heating. Journal of Food Science 73(6): C494-C499. https://doi. org/10.1111/j.1750-3841.2008.00845.x 